\title{
Changes of Muscle-Derived Cytokines in Relation to Thiol Redox Status and Reactive Oxygen and Nitrogen Species
}

\author{
A. ZEMBRON-LACNY ${ }^{1}$, M. NACZK ${ }^{2}$, M. GAJEWSKI ${ }^{3}$, J. OSTAPIUK-KAROLCZUK $^{1}$, \\ H. DZIEWIECKA ${ }^{1}$, A. KASPERSKA ${ }^{1}$, K. SZYSZKA ${ }^{1}$ \\ ${ }^{1}$ Department of Sport Medicine and Biochemistry, Faculty of Physical Culture Gorzow Wlkp., \\ University of Physical Education Poznan, Poland, ${ }^{2}$ Department of Physiology, Faculty of Physical \\ Culture Gorzow Wlkp., University of Physical Education Poznan, Poland, ${ }^{3}$ Department of Thoracic \\ Surgery, Medical University of Gdansk, Poland
}

Received February 18, 2010

Accepted May 7, 2010

On-line June 9, 2010

\begin{abstract}
Summary
The aim of this study was to compare the levels of the plasma muscle-derived cytokines (myokines) and reactive oxygen and nitrogen species (RONS) after muscle damage triggered by different exercises, and to demonstrate the relationships between RONS, thiol redox status and myokines. Sixteen young men participated in a $90-\mathrm{min}$ run at $65 \% \mathrm{VO}_{2} \max$ (Ex.1) or 90 -min run at $65 \% \mathrm{VO}_{2}$ max finished with a 15-min eccentric phase (Ex.2, downhill running). Plasma samples were collected before and at $20 \mathrm{~min}, 24 \mathrm{~h}$ and $48 \mathrm{~h}$ after exercise. The exercise trials significantly elevated the concentrations of plasma hydrogen peroxide $\left(\mathrm{H}_{2} \mathrm{O}_{2}\right)$ and 8-isoprostane at 20 min rest. Myokines IL-6 and IL-10 increased at $20 \mathrm{~min}$ rest while IL-1 $\beta$ and TNF $\alpha$ increased at $24 \mathrm{~h}$ rest following both running. Ex.2 caused a significant increase in nitric oxide (NO), IL-6, IL-10 and oxidized glutathione (GSSG) levels. Thiol redox status (GSH total2GSSG/GSSG) decreased by about $30 \%$ after Ex.2 as compared to Ex.1. $\mathrm{H}_{2} \mathrm{O}_{2}$ and NO directly correlated with IL-6, IL-10, IL-1 $\beta$, TNF $\alpha$ and glutathione. These results show that eccentric work is an important factor that enhances the production of RONS and muscle-derived cytokines, and that there is a possible participation of thiol redox status in the release of myokines to blood.
\end{abstract}

\section{Key words}

Muscle damage $\bullet$ Hydrogen peroxide $\bullet$ Nitric oxide $\bullet$ Thiol redox - Interleukins

\section{Corresponding author}

A. Zembron-Lacny, Department of Sports Medicine and Biochemistry, Faculty of Physical Culture Gorzow Wlkp., University of Physical Education Poznan, Estkowskiego 13, 66-400 Gorzow Wlkp., Poland. Fax: 0048957279158. E-mail: agzem@gorzow.home.pl

\section{Introduction}

The recent study has shown that reactive oxygen and nitrogen species (RONS) such as hydrogen peroxide $\left(\mathrm{H}_{2} \mathrm{O}_{2}\right)$ and nitric oxide (NO) are important signaling molecules generated during muscle contraction and are involved in the regeneration and adaptation of skeletal muscle to physical work. $\mathrm{H}_{2} \mathrm{O}_{2}$ and $\mathrm{NO}$ are produced by enzymes superoxide dismutase (SOD) and nitric oxide synthase (NOS) which are localized on the muscle sarcolemma (isoenzymes CuZnSOD and nNOS) and mitochondria (isoenzymes MnSOD and eNOS) (Jackson et al. 2007). The studies in human isolated muscle and myotube culture demonstrated that $\mathrm{H}_{2} \mathrm{O}_{2}$ and $\mathrm{NO}$ produced in the contracting skeletal muscle are key regulators of pretranslational signaling events leading to cytokines expression (Kosmidou et al. 2002, Steensberg et al. 2007).

The production of muscle-derived cytokines, called myokines (Pedersen and Febbraio 2005), is not directly induced by RONS but by thiol compounds, mainly glutathione. The ratio of reduced (GSH) to 
oxidized glutathione (GSSG) plays an essential role in regulation of thiol-dependent signaling pathways. Changes in thiol redox status lead to conformational changes in transcriptional factors, release inhibitory subunits, or promotion of protein complex formations which are necessary for signal transduction or transcription to proceed (Allen and Tresini 2000). Some cytokines such as IL-1 $\beta$ and TNF $\alpha$ amplify the signal through the enhancement of RONS generation and the decline in thiol redox state (Allen and Tresini 2000, Ji et al. 2006).

The cytokine response to physical exercise has been studied by many authors in recent years (Hirose et al. 2004, Peake et al. 2005, Petersen and Pedersen 2005, Plomgaard et al. 2005, Steensberg et al. 2002, Steinberg et al. 2007, Zoladz et al. 2009). The plasma myokines increase exponentially during or after physical effort in relation to exercise intensity and duration, mass of working muscles and type of contractions (concentric vs. eccentric). In spite of the large number of studies investigating the changes in cytokines, only a few other studies have compared the effects of different types of exercise on the muscle-derived cytokines (Brenner et al. 1999, Carmichael et al. 2005, Peake et al. 2005). In our previous study, we reported that IL- 6 dominated during the training period corresponding to performance of aerobic efforts, whereas TNF $\alpha$ reached the highest values during the start period when the anaerobic-alactate efforts and muscle damage were occurring (ZembronLacny et al. 2010). Based on these findings, the aim of the present study was to compare the effects of different types of exercise (with or without an eccentric phase) on changes in plasma muscle-derived cytokines and markers of muscle damage, and to examine the relationships between exercise-induced changes in RONS, thiol redox state and myokines in the blood.

\section{Methods}

Sixteen physically active untrained men (age $20.7 \pm 0.9$ years, height $167.7 \pm 6.9 \mathrm{~cm}$, body mass $74.0 \pm 6.5$ $\mathrm{kg}$ ) participated in the following exercise trials: in the exercise 1 (Ex.1) which involved 90-min run at $65 \%$ $\mathrm{VO}_{2} \max (0 \%$ gradient) and then in the exercise 2 (Ex.2) which involved 90-min run at $65 \% \mathrm{VO}_{2} \max (0 \%$ gradient) and 15 -min eccentric phase $(-10 \%$ gradient). The period between Ex.1 and Ex.2 was three months. Each subject was asked to avoid physical effort for $48 \mathrm{~h}$ before the exercise trials. During the study, subjects were also asked to avoid drugs or nutrition supplement that could interfere with immunological and pro-antioxidant evaluation. All the subjects were informed of the aim of the study and gave their written consent for participation in the project. The protocol of the study was approved by the local ethics committee in accordance with the Helsinki Declaration.

Blood samples were taken from antecubital vein to single-use containers with an anticoagulant $\left(\mathrm{EDTAK}_{2}\right)$ at pre-exercise and post-exercise periods $(20 \mathrm{~min}, 24 \mathrm{~h}$ and $48 \mathrm{~h}$ ). After collection, the samples were immediately placed in $4{ }^{\circ} \mathrm{C}$ temperature. Within $10 \mathrm{~min}$, they were centrifuged at $3000 \mathrm{~g}$ and $4{ }^{\circ} \mathrm{C}$ for $10 \mathrm{~min}$. Aliquots of plasma were stored at $-20{ }^{\circ} \mathrm{C}$ and analyzed within 7 days.

\section{Reactive oxygen and nitrogen species}

Plasma hydrogen peroxide $\left(\mathrm{H}_{2} \mathrm{O}_{2}\right)$ and nitric oxide (NO) concentrations were determined by using Oxis Research kit (USA). NO and $\mathrm{H}_{2} \mathrm{O}_{2}$ were measured immediately after plasma collection, at day of exercise study. $\mathrm{H}_{2} \mathrm{O}_{2}$ and $\mathrm{NO}$ detection limits were $6.25 \mu \mathrm{M}$ and $0.5 \mu \mathrm{M}$ respectively. The intra-assay coefficient of variation $(\mathrm{CV})$ for the $\mathrm{H}_{2} \mathrm{O}_{2}$ kit and for the $\mathrm{NO}$ kit it were $<10 \%$. Plasma 8 -isoprostanes, as a marker of RONS activity, were measured with Cayman kit (USA). 8-Isoprostane detection limit for the procedure was $2.7 \mathrm{pg} \cdot \mathrm{ml}^{-1}$, and the intra-assay coefficient of variation (CV) was $6.4 \%$.

\section{Thiol redox status}

Total $\left(\mathrm{GSH}_{\mathrm{t}}\right)$ and oxidized glutathione (GSSG) were measured with Oxis Research kit (USA). The concentrations of $\mathrm{GSH}_{\mathrm{t}}$ and GSSG were calculated using reduced glutathione as a standard and the results were expressed in $\mu \mathrm{mol} \cdot \mathrm{l}^{-1}$. Detection limits for the GSH and GSSG were $0.1 \mu \mathrm{mol} \cdot \mathrm{l}^{-1}$ and $0.02 \mu \mathrm{mol} \cdot 1^{-1}$, respectively. The intra-assay coefficients of variation (CV) for GSH and GSSG were $0.96 \%$ and $6.45 \%$, respectively. Thiol redox status was calculated according to the following equation: $\left(\mathrm{GSH}_{\mathrm{t}}-2 \mathrm{GSSG}\right) / \mathrm{GSSG}$. Before the measurement of glutathione, the blood samples were protected from oxidation according to the protocol of Oxis Research.

\section{Anti- and pro-inflammatory cytokines}

Plasma interleukin-6 (IL-6), interleukin-10, interleukin-1 $\beta$ (IL-1 $\beta$ ) and tumor necrosis factor (TNF $\alpha$ ) levels were determined by enzyme immunoassay methods using commercial kits (R\&D Systems, USA). 
Detection limits for IL-6, IL-10, IL-1 $\beta$ and TNF $\alpha$ were $0.039,0.500,0.023$ and $0.038 \mathrm{pg}^{\cdot} \mathrm{ml}^{-1}$, respectively. The average intra-assay coefficient of variation $(\mathrm{CV})$ was about $8.0 \%$ for all cytokines.

\section{Muscle damage}

Plasma creatine kinase (CK) activity was used as a marker of muscle damage and was evaluated by Emapol kit (Poland). CK detection limit for the applied kit was $6 \mathrm{U} \cdot 1^{-1}$. The intra-assay coefficient of variation (CV) for the CK kit was $1.85 \%$.

\section{Plasma volume}

Hemoglobin $(\mathrm{Hb})$, hematocrit (Hct) and immune cells number were assessed using Sysmex K-4500 (Poland). The post-exercise values were corrected for changes in plasma volume according to Kraemer and Brown (1986). Relative changes in plasma volume were calculated according to the following equation:

$\% \Delta \mathrm{PV}=100 \times\{([\mathrm{Hb}] 1 /[\mathrm{Hb}] 2) \times[100-(\mathrm{Hct} 2 \times 0.874] /$ $[100-(\operatorname{Hct} 1 \times 0.874)]-1\}$,

where $[\mathrm{Hb}] 1\left(\mathrm{~g} \cdot \mathrm{dl}^{-1}\right)$ and Hct1 (\%) are mean initial values, $[\mathrm{Hb}] 2$ and Hct2 are post-exercise values. The Hct was multiplied by 0.96 and 0.91 to correct for trapped plasma and peripheral sampling, respectively (Strauss et al. 1951).

\section{Statistical analysis}

Statistical calculations were performed using STATISTICA 8.0. Statistical significance was assessed by two-way repeated analysis of variance (ANOVA) and Tukey post-hoc test. Associations among measured parameters were analyzed using Pearson's linear regression (coefficient, $r$ ). Statistical significance was set at $P<0.05$. Results are expressed as mean \pm S.D.

\section{Results}

Muscle damage and immune cells (Table 1)

CK activity, as a marker of muscle damage, was higher after the trial with eccentric phase (Ex.2) than after Ex.1. Both Ex.1 and Ex.2 caused an increase in immune cells number at $20 \mathrm{~min}$ rest. Monocytes and neutrophils demonstrated a tendency to higher values after Ex.2 but the differences were insignificant. The number of neutrophils highly correlated with IL-6 and IL-10 (Table 4).

Table 1. Effect of exercise on activity of creatine kinase (CK) and number of immunological cells.

\begin{tabular}{|c|c|c|c|c|c|c|c|c|}
\hline & Pre-exercise & $\begin{array}{c}\text { Ex.1 vs. } \\
\text { Ex.2 }\end{array}$ & Rest 20 min & $\begin{array}{c}\text { Ex.1 vs. } \\
\text { Ex.2 }\end{array}$ & Rest 24 h & $\begin{array}{c}\text { Ex.1 vs. } \\
\text { Ex.2 }\end{array}$ & Rest 48 h & $\begin{array}{c}\text { Ex.1 vs. } \\
\text { Ex.2 }\end{array}$ \\
\hline \multicolumn{9}{|l|}{$C K\left(U \cdot l^{-1}\right)$} \\
\hline Exercise 1 & $118 \pm 28$ & $n s$ & $189 \pm 46$ & $P<0.05$ & $372 \pm 62 * *$ & $P<0.001$ & $278 \pm 79$ & $P<0.001$ \\
\hline Exercise 2 & $174 \pm 50$ & & $389 \pm 168 *$ & & $721 \pm 192 * * *$ & & $652 \pm 126^{* * *}$ & \\
\hline \multicolumn{9}{|c|}{ Leukocytes $\left(10^{-3} \cdot \mu l^{-1}\right)$} \\
\hline Exercise 1 & $5.74 \pm 0.95$ & $n s$ & $10.44 \pm 2.06^{* * *}$ & $n s$ & $6.14 \pm 1.30$ & $n s$ & $6.07 \pm 0.89$ & $n s$ \\
\hline Exercise 2 & $6.40 \pm 1.49$ & & $12.33 \pm 3.61 * * *$ & & $6.25 \pm 1.86$ & & $5.71 \pm 1.46$ & \\
\hline \multicolumn{9}{|c|}{ Monocytes $\left(10^{-3} \cdot \mu l^{-1}\right)$} \\
\hline Exercise 1 & $0.43 \pm 0.12$ & $n s$ & $0.64 \pm 0.12$ & $n s$ & $0.61 \pm 0.15$ & $n s$ & $0.63 \pm 0.13$ & $n s$ \\
\hline Exercise 2 & $0.41 \pm 0.09$ & & $0.71 \pm 0.19^{* *}$ & & $0.56 \pm 0.17$ & & $0.50 \pm 0.13$ & \\
\hline \multicolumn{9}{|c|}{ Neutrophils $\left(10^{-3} \cdot \mu t^{-1}\right)$} \\
\hline Exercise 1 & $3.06 \pm 0.57$ & $n s$ & $8.58 \pm 1.57 * * *$ & $n s$ & $3.44 \pm 0.60$ & $n s$ & $3.13 \pm 0.56$ & $n s$ \\
\hline Exercise 2 & $4.32 \pm 0.87$ & & $9.58 \pm 1.71 * * *$ & & $4.28 \pm 1.26$ & & $4.09 \pm 1.82$ & \\
\hline \multicolumn{9}{|c|}{ Lymphocytes $\left(10^{-3} \cdot \mu l^{-1}\right)$} \\
\hline Exercise 1 & $1.96 \pm 0.27$ & $n s$ & $1.71 \pm 0.31$ & $n s$ & $2.01 \pm 0.36$ & $n s$ & $1.94 \pm 0.25$ & $n s$ \\
\hline Exercise 2 & $2.53 \pm 0.37$ & & $1.96 \pm 0.44$ & & $1.86 \pm 0.38^{*}$ & & $1.86 \pm 0.56^{*}$ & \\
\hline
\end{tabular}

Exercise $1-90 \mathrm{~min}$ run at $65 \% \mathrm{VO}_{2} \max$. Exercise $2-90$ min run at $65 \% \mathrm{VO}_{2}$ max and 15 min eccentric phase. $* P<0.05, * * P<0.01$, $* * * P<0.001$ indicate post-exercise vs. pre-exercise values. 
Table 2. Effect of exercise on concentrations of hydrogen peroxide $\left(\mathrm{H}_{2} \mathrm{O}_{2}\right)$, nitric oxide (NO), 8-isoprostane, total $\left(\mathrm{GSH}_{\mathrm{t}}\right)$ and oxidized glutathione (GSSG).

\begin{tabular}{|c|c|c|c|c|c|c|c|c|}
\hline & Pre-exercise & $\begin{array}{c}\text { Ex.1 vs. } \\
\text { Ex.2 }\end{array}$ & Rest 20 min & $\begin{array}{c}\text { Ex.1 vs. } \\
\text { Ex.2 }\end{array}$ & Rest 24 h & $\begin{array}{c}\text { Ex.1 vs. } \\
\text { Ex.2 }\end{array}$ & Rest 48 h & $\begin{array}{c}\text { Ex.1 vs. } \\
\text { Ex.2 }\end{array}$ \\
\hline \multicolumn{9}{|c|}{$\mathrm{H}_{2} \mathrm{O}_{2}\left(\mathrm{mmol} \cdot \mathrm{ml}^{-1}\right)$} \\
\hline Exercise 1 & $3.09 \pm 0.88$ & $n s$ & $5.97 \pm 1.06^{* * *}$ & $n s$ & $4.92 \pm 0.95^{*}$ & $n s$ & $4.16 \pm 0.95$ & $n s$ \\
\hline Exercise 2 & $2.74 \pm 0.86$ & & $6.05 \pm 1.43^{* * *}$ & & $4.19 \pm 0.89$ & & $5.29 \pm 0.52 * * *$ & \\
\hline \multicolumn{9}{|c|}{$N O\left(\mathrm{mmol} \cdot \mathrm{ml}^{-1}\right)$} \\
\hline Exercise 1 & $26.44 \pm 3.49$ & $n s$ & $28.65 \pm 3.21$ & $n s$ & $29.87 \pm 5.32$ & $P<0.001$ & $32.92 \pm 4.81$ & $n s$ \\
\hline Exercise 2 & $31.42 \pm 4.45$ & & $33.55 \pm 4.89$ & & $46.60 \pm 5.98^{* * *}$ & & $35.87 \pm 5.61$ & \\
\hline \multicolumn{9}{|c|}{ 8-isoprostane $\left(p g \cdot m l^{-1}\right)$} \\
\hline Exercise 1 & $29.47 \pm 6.30$ & $n s$ & $40.08 \pm 5.95^{*}$ & $n s$ & $30.19 \pm 6.39$ & $n s$ & $28.22 \pm 4.93$ & $n s$ \\
\hline Exercise 2 & $24.38 \pm 7.85$ & & $40.92 \pm 5.91 * * *$ & & $22.00 \pm 6.25$ & & $27.68 \pm 7.76$ & \\
\hline \multicolumn{9}{|c|}{$G S H_{t}\left(\mathrm{mmol}^{\prime} \mathrm{ml}^{-1}\right)$} \\
\hline Exercise 1 & $721 \pm 118$ & $n s$ & $1016 \pm 161 * *$ & $n s$ & $978 \pm 150^{* *}$ & $n s$ & $987 \pm 138^{* *}$ & $n s$ \\
\hline Exercise 2 & $726 \pm 105$ & & $967 \pm 67^{*}$ & & $1010 \pm 125^{* *}$ & & $843 \pm 124$ & \\
\hline \multicolumn{9}{|c|}{$G S S G\left(m m o l \cdot l^{-1}\right)$} \\
\hline Exercise 1 & $6.90 \pm 1.58$ & $n s$ & $7.69 \pm 1.78$ & $P<0.01$ & $7.91 \pm 1.61$ & $P<0.01$ & $7.73 \pm 1.19$ & $n s$ \\
\hline Exercise 2 & $7.84 \pm 0.83$ & & $10.86 \pm 1.88^{* *}$ & & $11.04 \pm 1.95^{* *}$ & & $10.31 \pm 1.77$ & \\
\hline
\end{tabular}

Exercise $1-90 \mathrm{~min}$ run at $65 \% \mathrm{VO}_{2}$ max. Exercise $2-90 \mathrm{~min}$ run at $65 \% \mathrm{VO}_{2}$ max and 15 min eccentric phase. $* P<0.05, * * P<0.01$, $* * * P<0.001$ indicate post-exercise vs. pre-exercise values.

Table 3. Effect of exercise on anti- (IL-6, IL-10) and pro-inflammatory (IL-1 $\beta$, TNF $\alpha$ ) cytokines.

\begin{tabular}{|c|c|c|c|c|c|c|c|c|}
\hline & Pre-exercise & $\begin{array}{c}\text { Ex.1 vs. } \\
\text { Ex.2 }\end{array}$ & Rest 20 min & $\begin{array}{c}\text { Ex.1 vs. } \\
\text { Ex.2 }\end{array}$ & Rest 24 h & $\begin{array}{c}\text { Ex.1 vs. } \\
\text { Ex.2 }\end{array}$ & Rest 48 h & $\begin{array}{l}\text { Ex.1 vs. } \\
\text { Ex.2 }\end{array}$ \\
\hline \multicolumn{9}{|c|}{$I L-6\left(p g \cdot m l^{-1}\right)$} \\
\hline Exercise 1 & $1.33 \pm 0.17$ & $n s$ & $6.50 \pm 1.24 * * *$ & $P<0.05$ & $1.91 \pm 0.65$ & $P<0.05$ & $1.57 \pm 0.30$ & $P<0.05$ \\
\hline Exercise 2 & $1.90 \pm 0.32$ & & $7.81 \pm 1.22 * * *$ & & $3.27 \pm 0.85$ & & $2.86 \pm 0.82$ & \\
\hline \multicolumn{9}{|c|}{$I L-10 \mathrm{pg} \cdot\left(m l^{-1}\right)$} \\
\hline Exercise 1 & $7.61 \pm 0.87$ & $n s$ & $16.48 \pm 5.87 * * *$ & $P<0.01$ & $8.44 \pm 1.13$ & $P<0.001$ & $8.85 \pm 1.70$ & $P<0.001$ \\
\hline Exercise 2 & $10.03 \pm 1.78$ & & $19.23 \pm 2.47^{* * *}$ & & $13.51 \pm 1.31$ & & $13.45 \pm 1.76$ & \\
\hline \multicolumn{9}{|c|}{$I L-1 \beta p g \cdot\left(m l^{-1}\right)$} \\
\hline Exercise 1 & $0.60 \pm 0.13$ & $n s$ & $0.81 \pm 0.17$ & $n s$ & $0.89 \pm 0.10^{*}$ & $n s$ & $0.86 \pm 0.11$ & $n s$ \\
\hline Exercise 2 & $0.66 \pm 0.14$ & & $0.73 \pm 0.15$ & & $0.98 \pm 0.15^{* * *}$ & & $0.83 \pm 0.12$ & \\
\hline \multicolumn{9}{|c|}{$T N F \alpha\left(p g \cdot m l^{-1}\right)$} \\
\hline Exercise 1 & $2.97 \pm 0.38$ & $n s$ & $3.52 \pm 0.70$ & $n s$ & $4.39 \pm 0.46^{* * *}$ & $n s$ & $3.94 \pm 0.67 * *$ & $n s$ \\
\hline Exercise 2 & $3.02 \pm 0.43$ & & $3.37 \pm 0.47$ & & $5.34 \pm 0.67 * * *$ & & $3.59 \pm 0.61$ & \\
\hline
\end{tabular}

Exercise $1-90 \mathrm{~min}$ run at $65 \% \mathrm{VO}_{2}$ max. Exercise $2-90$ min run at $65 \% \mathrm{VO}_{2}$ max and 15 min eccentric phase. $* P<0.05, * * P<0.01$, $* * * P<0.001$ indicate post-exercise vs. pre-exercise values.

\section{Reactive oxygen and nitrogen species (Table 2)}

The exercise trials significantly elevated the concentrations of plasma $\mathrm{H}_{2} \mathrm{O}_{2}$ and 8-isoprostane at 20 min rest. There were no differences between Ex.1 and Ex.2. During recovery, the level of $\mathrm{H}_{2} \mathrm{O}_{2}$ and 8-isoprostane returned to initial values. NO concentration increased at $24 \mathrm{~h}$ after exercise only when the eccentric phase was applied (Ex.2). This can mean that eccentric contractions are more essential for the stimulation of NO than $\mathrm{H}_{2} \mathrm{O}_{2}$ synthesis. 


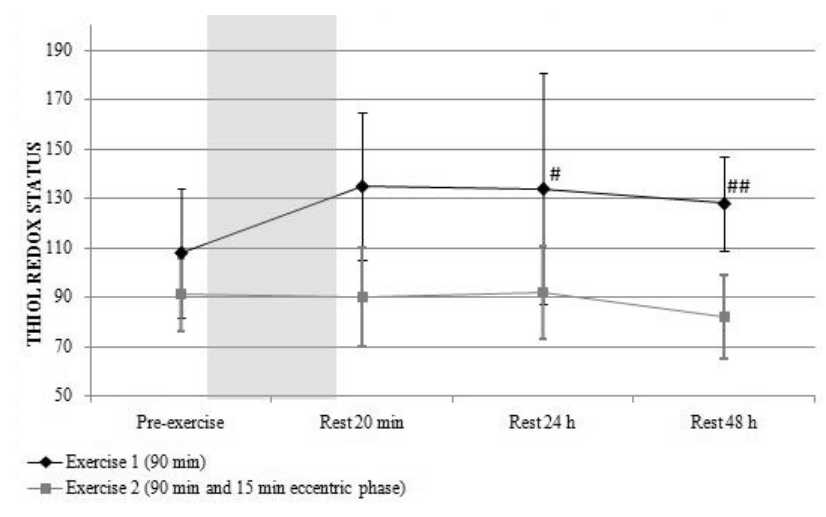

Fig. 1. Changes in blood thiol redox status $\left(\mathrm{GSH}_{\mathrm{t}}-2 \mathrm{GSSG} / \mathrm{GSSG}\right)$; ${ }^{\#} P<0.05$, ${ }^{\# \#} P<0.01$ indicate Exercise 1 vs. Exercise 2; grey area indicates exercise.

\section{Thiol redox status (Table 2)}

GSH concentration increased by $30-40 \%$ at $20 \mathrm{~min}$ and $24 \mathrm{~h}$ after both exercise trials, while GSSG increased by $40 \%$ only after the running with eccentric phase (Ex.2). Finally, thiol redox status declined after Ex.2 compared to Ex.1, and it remained on the low level up to $48 \mathrm{~h}$ rest (Fig.1). This means that eccentric exercise elevates the glutathione oxidation and delays the return to redox balance during recovery.

\section{Anti- and pro-inflammatory cytokines (Table 3)}

The changes in levels of anti- and proinflammatory cytokines took place at different time points. IL- 6 and IL-10 increased at 20 min while IL-1 $\beta$ and TNF $\alpha$ increased at $24 \mathrm{~h}$ after both exercise trials. However, the response of anti-inflammatory cytokine IL-6 and IL-10 was significantly higher when the eccentric phase was applied. IL-6 and IL-10 correlated significantly with $\mathrm{H}_{2} \mathrm{O}_{2}, 8$-isoprostanes and also neutrophils after Ex.1 and Ex.2 (Table 4), whereas IL-1 $\beta$ and TNF $\alpha$ correlated with NO concentration after Ex.2 (IL-1 $\beta / \mathrm{NO}: \mathrm{r}=0.458, P<0.01 ; \mathrm{TNF} \alpha / \mathrm{NO}: \mathrm{r}=0.660$, $P<0.001)$.

\section{Discussion}

Eccentric exercise has been used widely for inducing muscle damage and may be a valuable tool in the study of inflammation. The muscle tissue damage promotes infiltration by inflammatory cells that, in conjunction with local muscle, endothelial, and satellite cells, produce an array of molecules to regulate the regeneration process, including TNF $\alpha$, IL-1 $\beta$, IL-6, IL-10 and RONS. Typical responses to muscle injury induced by eccentric exercise include loss of force-generating
Table 4. Relationships (correlation coefficients) between antiinflammatory cytokines (IL-6 and IL-10) and hydroperoxide $\left(\mathrm{H}_{2} \mathrm{O}_{2}\right)$, 8-isoprostanes and neutrophils in Ex.1 and Ex.2 experiments.

\begin{tabular}{llll}
\hline & $\mathbf{H}_{2} \mathbf{O}_{\mathbf{2}}$ & 8-isoprostanes & neutrophils \\
\hline $\boldsymbol{I L - 6}$ & & & \\
Exercise 1 & $0.575^{* * *}$ & $0.620^{* * *}$ & $0.908^{* * *}$ \\
Exercise 2 & $0.547^{* *}$ & $0.653^{* * *}$ & $0.847^{* * *}$ \\
$\boldsymbol{I L - 1 0}$ & & & \\
Exercise 1 & $0.543^{* * *}$ & $0.419^{* * *}$ & $0.678^{* * *}$ \\
Exercise 2 & $0.572^{* *}$ & $0.531^{* *}$ & $0.809^{* * *}$ \\
\hline
\end{tabular}

$* P<0.05, * * P<0.01, * * * P<0.001$.

capacity, decreased range of motion, delayed-onset muscle soreness, swelling, and delayed increases in circulating intramuscular proteins e.g. creatine kinase (Peake et al. 2005, Miles et al. 2008, Power and Jackson 2008).

Our results show that running exercise with eccentric phase (Ex.2) caused a considerable damage in skeletal muscle expressed with the high activity of CK and the shift in immune cells, mainly monocytes and neutrophils, which can be an additional source of RONS within muscle. The presence of muscle injury particularly impacted on NO release at $24 \mathrm{~h}$. Recently Lima et al. (2009) demonstrated that eccentric exercise modulates the expression of three isoenzymes of nitric synthase (NOS) in skeletal muscle through the signaling pathways controlled by nuclear factor $\kappa B \quad(\mathrm{NF} \kappa B)$. The transcription factor $\mathrm{NF \kappa B}$ is activated by $\mathrm{H}_{2} \mathrm{O}_{2}$, which also generated by contracting skeletal muscle (Ji et al. 2006). $\mathrm{H}_{2} \mathrm{O}_{2}$ and $\mathrm{NO}$ are involved in transcriptional control through thiol redox modification or nitrosation of many transcription factors which induce the expression of many molecules such as cytokines and growth factors (Hemish et al. 2003, Ji et al. 2006, Jackson et al. 2007, Steensberg et al. 2007). Our demonstration of the correlations between blood levels of $\mathrm{H}_{2} \mathrm{O}_{2}$, NO, IL-6, IL10 , IL-1 $\beta$ and TNF $\alpha$ are in line with the relations between RONS generation and cytokine response that were observed in isolated human muscle and myotube culture.

The thiol redox status participates in cellular signaling pathways linking the generation of RONS with the activation of transcription factors and their ability to bind with DNA (Allen and Tresini 2000, Ji et al. 2006). It was confirmed that the thiol reducing agents, such as $\mathrm{N}$ acetyl-L-cysteine, block activation of transcription factors 
and cytokines synthesis, whereas the oxidants, such as $\mathrm{H}_{2} \mathrm{O}_{2}$, have the opposite effects (Allen and Tresini 2000, Kosmidou et al. 2002, Ji et al. 2006). We observed that $\mathrm{H}_{2} \mathrm{O}_{2}$ and $\mathrm{GSH}$ increased in both exercise trials, while NO and GSSG increased only when eccentric phase was applied. This may mean that NO plays a more important role in glutathione oxidation and thiol redox disturbance than $\mathrm{H}_{2} \mathrm{O}_{2}$.

The analysis of muscle-derived cytokines in blood showed an increase in IL-6 and IL-10 after both exercise trials at $20 \mathrm{~min}$ and the enhanced increase in IL-6 and IL-10 following Ex.2. The levels of IL-6 and IL-10 remained elevated $48 \mathrm{~h}$ after Ex. 2 as compared with values after Ex.1. According to Petersen and Pedersen (2005), IL-6 is essential regulator of the proliferation of satellite cells and differentiation of myoblasts. The genetic loss of IL-6 blunts the muscle regeneration and hypertrophy in vivo (Serrano et al. 2008). The cytokines IL-1 $\beta$ and TNF $\alpha$ increased during recovery at $24 \mathrm{~h}$. The long-term presence of proinflammatory cytokines can also be related to muscle restoration, but $\mathrm{TNF} \alpha$ presence in muscle regeneration is not an absolute requirement (Cannon et al. 1989, Collins and Grounds 2001, Reid and Li 2001). It should be stressed that the suppression of inflammatory response by anti-inflammatory drugs attenuates the exercise-induced increase in satellite cell number after eccentric exercise (Mackey et al. 2007). Based on these results, we conclude that high level of myokines, particularly IL-6 and IL-10, can be a marker of a normal reconstruction of muscle after intense exercise and adaptation to physical exercise. Recently, we observed that professional sport training significantly influences plasma cytokine levels. IL-6 was significantly higher in the preparatory period than in the play-off round in professional basketball players (Zembron-Lacny et al. 2010).

An important finding of our study was the integration of RONS production with cytokine response. We observed the correlations between $\mathrm{H}_{2} \mathrm{O}_{2}$ and antiinflammatory cytokines after both exercise trials. Moreover, the high level of NO enhanced the release of IL-6 and IL-10 after Ex.2. The recent exercise study in humans demonstrated that NO is the key regulator of pretranslational signaling events leading to muscle IL-6 production. Pharmacological inhibition of NO production during exercise attenuated the increase in IL-6 mRNA levels in human skeletal muscle, whereas intra-arterial infusion of an NO donor was accompanied by increase in IL-6 mRNA (Steensberg et al. 2007). Both NO and $\mathrm{H}_{2} \mathrm{O}_{2}$ activates transcription factor NFKB loading to IL-6 expression in skeletal muscle (Kosmidou et al. 2002, Lima et al. 2009). The combination of exercise duration with eccentric work (downhill running) increases the NO and $\mathrm{H}_{2} \mathrm{O}_{2}$ generation as well as the release of IL- 6 and IL-10 from the skeletal muscle, which can improve the adaptation of organism to intense physical exercise.

Our results 1) show that eccentric work is an important factor enhancing the production of nitric oxide, oxidized glutathione and anti-inflammatory cytokines, 2) confirm the relation of RONS generation with musclederived cytokines release, and 3) indicate a possible involvement of blood thiol redox in myokines synthesis.

\section{Conflict of Interest}

There is no conflict of interest.

\section{Acknowledgements}

This study was supported by a grant NN404 155534 from the Ministry of Science and Higher Education, Poland.

\section{References}

ALLEN GR, TRESINI M: Oxidative stress and gene regulation. Free Radic Biol Med 28: 463-499, 2000.

BRENNER IK, NATALE VM, VASILIOU P, MOLDOVEANU AI, SHEK PN, SHEPARD RJ: Impact of tree different types of exercise on components of the inflammatory response. Eur J Appl Physiol 80: 452-460, 1999.

CANNON JG, FIELDING RA, FIATARONE MA, ORENCOLE SF, DINARELlO CA, EVANS WJ: Increased interleukin $1 \beta$ in human skeletal muscle after exercise. Am J Physiol 257: 451-455, 1989.

CARMICHAEL MD, DAVIS JM, MURPHY EA, BROWN AS, CARSON JA, MAYER E, GHAFFAR A: Recovery of running performance following muscle-damaging exercise: relationship to brain IL-1beta. Brain Behav Immun 19: 445-452, 2005.

COLLINS RA, GROUNDS MD: The role of tumour necrosis factor-alpha (TNF-alpha) in skeletal muscle regeneration: studies in TNF-alpha(-/-) and TNF-alpha(-/-)/LT-alpha(-/-) mice. J Histochem Cytochem 49: 989-1001, 2001. 
HEMISH J, NAKAYA N, MITTAL V, ENIKOLOPOV G: Nitric oxide activates diverse signalling pathways to regulate gene expression. J Biol Chem 278: 42231-42329, 2003.

HIROSE L, NOSAKA K, NEWTON M: Changes in inflammatory mediarors following eccentric exercise of the elbow flexors. Exerc Immunol Rev 10: 75-90, 2004.

JACKSON MJ, PYE D, PALOMERO J: The production of reactive oxygen and nitrogen species by skeletal muscle. J Appl Physiol 102: 1664-1670, 2007.

JI LL, GOMEZ-CABRERA MC, VINA J: Exercise and hormesis. Activation of cellular antioxidant signalling pathway. Ann NY Acad Sci 1067: 425-435, 2006.

KOSMIDOU I, VASSILAKOPOULOUS T, XAGORARI A, ZAKYNTHINOS S, PAPAPETROPOULOS A, ROUSSOS C: Production of interleukin-6 by skeletal myotubes. Role of reactive oxygen species. Am J Respir Cell Mol Biol 26: 587-593, 2002.

KRAEMER RR, BROWN BS: Alternations in plasma-volume-corrected blood components of marathon runners and concomitant relationship to performance. Eur J Appl Physiol 55: 579-584, 1986.

MACKEY AL, KJAER M, DANDANELL S, MIKKELSEN KH, HOLM L, DØSSING S, KADI F, KOSKINEN SO, JENSEN CH, SCHRØDER HD, LANGBERG H: The influence of anti-inflammatory medication on exerciseinduced myogenic precursor cell responses in humans. J Appl Physiol 103: 425-431, 2007.

MILES MP, ANDRING JM, PEARSON SD, GORDON LK, KASPER C, DEPNER DM, KIDD JR: Diurnal variation, response to eccentric exercise, and association of inflammatory mediators with muscle damage variables. J Appl Physiol 104: 451-458, 2008.

PEAKE J, NOSAKA K, SUZUKI K: Characterization of inflammatory responses to eccentric exercise in humans. Exerc Immunol Rev 11: 64-85, 2005.

PEDERSEN BK, FEBBRAIO M: Muscle-derived interleukin-6 - a possible link between skeletal muscle, adipose tissue, liver, and brain. Brain Behav Immun 19: 371-376, 2005.

PETERSEN AMW, PEDERSEN BK: Anti-inflammatory effect of exercise. $J$ Appl Physiol 98: 1154-1162, 2005.

PLOMGAARD P, PENKOVA M, PEDERSEN BK: Fiber type specific expression of TNF-alpha, IL-6 and IL-18 in human skeletal muscles. Exerc Immunol Rev 11: 53-64, 2005.

POWER SK, JACKSON MJ: Exercise-induced oxidative stress: cellular mechanisms and impact on muscle force production. Physiol Rev 88: 1243-1276, 2008.

REID MB, LI YP: Tumour necrosis factor-alpha and muscle wasting: a cellular perspective. Respir Res 2: 269-272, 2001.

STEENSBERG A, KELLER C, HILLIG T, FROSIG C, WOJTASZEWSKI JF, PEDERSEN BK, PILEGAARD H, SANDER M: Nitric oxide production is a proximal signalling event controlling exercise-induced mRNA expression in human skeletal muscle. FASEB $J$ 21: 2683-2694, 2007.

STEINBERG JG, BA A, BREGEON F, DELLIAUX S, JAMMES Y: Cytokine and oxidative responses to maximal cycling exercise in sedentary subjects. Med Sci Sports Exerc 39: 964-968, 2007.

STRAUSS MB, DAVIS RK, ROSENBAUM JD, ROSSMEISL EC: Water diuresis produced during recumbency by the intravenous infusion of isotonic saline solution. J Clin Invest 30: 862-868, 1951.

ZEMBRON-LACNY A, SLOWINSKA-LISOWSKA M, ZIEMBA A: Integration of the thiol redox status with cytokine response to physical training in professional basketball players. Physiol Res 59: 239-245, 2010.

ZOLADZ JA, MAJERCZAK J, DUDA K, CHLOPICKI S: Exercise-induced prostacyclin release positively correlates with $\mathrm{VO}_{2}$ max in young healthy men. Physiol Res 58: 229-238, 2009. 